DOI: http://dx.doi.org/10.5007/2175-7941.2014v31n2p289

\title{
Os Procedimentos Discursivos Didáticos como saberes experienciais exemplares de um formador de professo- res de física ${ }^{+*}$
}

Rodrigo Drumond Vieira

Viviane Florentino de Melo

Bolsista técnica - Universidade Federal Fluminense

José Roberto da Rocha Bernardo

Universidade Federal Fluminense

Niteroi - RJ

\section{Resumo}

Neste artigo partimos da problemática da profissionalização do ensino e dos saberes docentes para apresentar e discutir a nossa proposta discursiva para investigação de saberes docentes experienciais de um professor formador experiente da área de didática da fisica. Nossas análises privilegiam os saberes experienciais que temos chamado de "Procedimentos Discursivos Didáticos" (PDD), que são os meios (mecanismos) pelos quais os professores satisfazem seus objetivos didáticos e gerenciam o discurso estabelecido em sala de aula. A objetividade dos saberes experienciais assim identificados se baseia no caráter argumentativo, evidenciado pelas análises discursivas. Consideramos que a análise e mapeamento desses procedimentos pela pesquisa podem informar a prática de outros professores, contribuindo assim para a transformação de ideias e práticas. Concluímos reforçando a necessidade de compor um quadro procedimental mais amplo, que envolva a

\footnotetext{
The Discursive Didactic Procedures as exemplary practical knowledge of a Physics teacher trainer

* Recebido: junho de 2013.

Aceito: dezembro de 2013.
} 
diversidade discursiva presente em aulas de formação de professores de ciências e de fisica em particular.

Palavras-Chave:

Palavras-chave: Saberes docentes. Procedimentos Discursivos Didáticos. Formação de professores de física.

\begin{abstract}
From discussions regarding the professionalization of education and the teachers' professional knowledge, in this paper we present our discursive approach to investigate the practical knowledge of an experienced physics teacher trainer. The analyses focus on his practical knowledge that we have called "Discursive Didactic Procedures" (DDP). The DDP are the means by which the teachers' pursue their didactic goals and manage the discourse within their classrooms. The objectivity of such practical knowledge is assured by its argumentative character evinced by discourse analysis. We consider that the analysis and mapping of these procedures can inform other teachers' practices, thus contributing for transformation of ideas and practices. We conclude reinforcing the need to compose and increase a repertory about the teachers' procedures that encompass the diversity of science and physics classes in teacher education.
\end{abstract}

Keywords: Professional knowledge. Discursive Didactic Procedures. Physics teacher education.

\title{
I. Introdução
}

A problemática da profissionalização do ensino levou a indagações sobre os saberes inerentes à prática docente, tendo em vista o objetivo de tirar a docência da categoria ofício e situá-la enquanto profissão, em que os professores seriam detentores, produtores e controladores de saberes próprios ao seu trabalho. Tal situação levou muitos teóricos a inquirir sobre qual seria a natureza desse saber específico, sendo que a síntese realizada por Shulman (1986) é considerada um marco e uma forte referência para o campo, pois estabeleceu um domínio de conhecimento composto dos demais e enriquecido deles, pois submetido à prática $-\mathrm{o}$ 
Conhecimento Pedagógico de Conteúdo (do inglês Pedagogical Content Knowled$g e$, PCK). Esse conhecimento se estabelece como uma integração, na e pela prática, de conhecimentos de conteúdo, conhecimentos pedagógicos e conhecimentos contextuais. Assim, trata-se de um conhecimento sobre como ensinar determinado conteúdo por intermédio de estratégias pedagógicas para um determinado grupo de estudantes situados em um contexto específico.

A pesquisa sobre os saberes docentes evoluiu bastante desde a apresentação do programa de pesquisa de Shulman. Autores como Gauthier e colegas (1998) e Tardif (2002) esforçaram-se para construir uma teoria integrada sobre os saberes docentes, delineando uma epistemologia da prática profissional e a proposição de abordagens metodológicas com vistas a estudar a emergência e as representações desses saberes pelos docentes. Além disso, os autores buscaram apontar a origem social e a natureza dos saberes docentes.

Mais especificamente, com relação à investigação dos saberes docentes, o trabalho de Borges (2004) apresenta críticas a algumas abordagens cognitivistas e etnográficas extremas, alegando que a primeira eleva o professor a uma hiperracionalidade e a segunda considera como saber tudo que o professor faz em sala de aula. $\mathrm{O}$ trabalho da autora tende a uma abordagem cognitivista atenuada, em que o critério de racionalidade (que a autora utiliza como definidor do status de saber) repousa sobre o caráter argumentativo dos saberes docentes explicitados pelos sujeitos de pesquisa em situações de entrevista.

Sob esse ponto de vista, não é suficiente que o professor faça determinadas coisas para que isso seja considerado saber, é preciso que ele saiba por que fez essas coisas ou por que fez desta ou daquela forma. Ou seja, o saber docente constitui aquilo que os sujeitos são capazes de explicitar da sua prática e de justificar devidamente.

A própria autora reconhece as limitações da sua opção teóricometodológica, bastante centrada no ponto de vista dos sujeitos e alheia ao olhar externo do pesquisador sobre a ação docente por meio da observação. Conforme apontado por ela, uma alternativa interessante para sanar tais limitações seriam as

\footnotetext{
${ }^{1}$ Segundo Tardif (2000): “chamamos de epistemologia da prática profissional o estudo do conjunto dos saberes utilizados realmente pelos professores em seu espaço de trabalho cotidiano para desempenhar todas as suas tarefas". O autor salienta que o que chama de saber é investido de um caráter bastante amplo, englobando os conhecimentos, as competências, as habilidades e as atitudes, ou seja, aquilo que já foi chamado muitas vezes de saber, saber fazer e saber ser.
} 
abordagens da cognição situada, em que "muitos pesquisadores lançam mão da observação e do stimulated-recall, isto é, após a observação e registro minucioso da situação, parte-se para uma entrevista na qual o docente é estimulado a verbalizar sua ação e os motivos que o fizeram agir de uma ou outra forma" (BORGES, 2004, p. 92).

Tendo como panorama esse quadro geral sobre os saberes docentes, nosso objetivo neste trabalho é apresentar e discutir a nossa abordagem discursiva para investigação dos saberes docentes, cuja objetividade e racionalidade são garantidas pelo caráter argumentativo das análises. De início, vamos apresentar uma pequena síntese sobre a investigação dos saberes docentes, em especial os saberes experienciais. Em seguida, apresentaremos discussão sobre o que temos chamado de "Procedimentos Discursivos Didáticos" (PDD), que são os meios pelos quais o professor gerencia e conduz o discurso de sala de aula. Por meio das análises, mostramos como um conjunto de PDD singulares destacados da prática de um formador experiente pode ser considerado um saber experiencial exemplar, podendo servir de referência para outros professores e para a formação, constituindo e aumentando o que Gauthier e colegas (1998) chamam de um "repertório de conhecimentos" disponível para os professores.

\section{Quadro teórico: Os saberes docentes como objeto de investigação}

\section{II.1 A natureza e origem social dos saberes docentes}

Tardif (2002) identificou quatro fontes dos saberes docentes: os "saberes da formação profissional", os "saberes das disciplinas", os "saberes curriculares" e os "saberes da experiência". Suas características gerais são:

Saberes da formação profissional: conjunto de saberes que são transmitidos pelas instituições formadoras de professores (como as faculdades de ciências da educação e as escolas normais) e do conjunto das doutrinas pedagógicas, constitutivas de sistemas de representação da prática docente (sistemas ideológicos) que muitas vezes se justificam por meio dos resultados de pesquisas em ciências da educação.

Saberes disciplinares: saberes sociais definidos pela Universidade e que correspondem aos diversos campos do conhecimento de que dispõe a sociedade. São transmitidos pelos cursos de departamentos universitários de forma independente das faculdades de educação e dos cursos de formação de professores (e.g., 
matemática, literatura, geografia, etc.). São, enfim, saberes que emergem da tradição cultural e dos grupos sociais produtores de saberes;

Saberes curriculares: correspondem aos discursos, objetivos, conteúdos e métodos através dos quais a instituição escolar seleciona, categoriza e apresenta os saberes sociais que devem ser ensinados. São encontrados em programas escolares que os professores devem se apropriar e utilizar em sua prática profissional;

Saberes experienciais: são saberes que os professores desenvolvem no âmbito do seu trabalho cotidiano que emergem da experiência e que são validados por ela. Por isso, podem ser chamados também de saberes práticos.

Tais distinções são importantes, pois permitem reconhecer que os professores muitas vezes mantêm relações de "transmissores", de "portadores" ou de "objeto" com os saberes, mas não como produtores de saberes que possam ser legitimados por eles e que venham a definir o espaço social e profissional da sua prática. Em suma, a profissão docente se define em relação aos saberes apresentados, mas eles não são produzidos nem controlados por aqueles que exercem efetivamente a docência. Isso constitui um problema, pois a prática docente se submete a saberes que ela não produz e nem controla, com exceção dos conhecimentos experienciais, que brotam da prática concreta dos professores.

Reconhecemos que os professores são produtores legítimos desse tipo de saber (experiencial ou prático) e é com relação a ele que devemos procurar estabelecer um repertório que seja, ao mesmo tempo, específico, produzido e controlado pelos próprios professores e que venha a definir a especificidade da profissão docente. Assim, na próxima seção vamos discutir em detalhes a natureza desse tipo de saber e como ele se relaciona com os demais saberes.

\section{II.2 Os saberes experienciais ou práticos}

Essa é uma categoria especial de saberes, pois, como salientamos acima, eles brotam da prática concreta dos professores. Os saberes práticos não são aqueles utilizados para se conhecer melhor a prática; antes, se integram a ela e dela emergem, constituindo o que Tardif (2002) chama de "cultura docente em ação".

E como tais saberes podem ser considerados objetivos? Tardif (2002) responde a essa questão apontando para o compartilhamento dos saberes entre os pares. Assim, é no confronto entre os diversos saberes produzidos pela experiência singular de cada docente que eles adquirem um caráter de objetividade: as certezas subjetivas se tornam objetivas no momento em que se transformam num discurso da experiência, que pode informar e formar outros docentes e fornecer respostas 
para os seus problemas. Desse ponto de vista surge a perspectiva do docente como prático, mas também como formador, uma vez que deve tomar consciência de seus próprios saberes para transmiti-los, objetivando-os, tanto para si quanto para os outros. Disso decorre a necessidade de promover espaços privilegiados para as trocas de experiências entre os docentes enquanto âmbitos de formação permanente.

A pesquisa adquire, nesse quadro, um papel de grande importância, pois a consideramos em sua dupla função de explicitar e justificar os saberes docentes, tirando-os do segredo de sala de aula. É nessa perspectiva que se torna necessário estabelecer um "repertório de conhecimentos" de referência para os docentes (GAUTHIER, et. al, 1998).

Mas quais critérios o pesquisador deve seguir para selecionar o seu locus e os sujeitos de pesquisa para atender o objetivo de explicitar seus saberes e ampliar o "repertório de conhecimentos" disponível para os docentes?

Ao invés de abordarmos possibilidades horizontalmente, apresentaremos o nosso ponto de vista, justificando-o numa característica do saber docente amplamente conhecida e discutida: a característica de integrar todos os outros saberes em uma amálgama.

\section{II.3 A amálgama e a seleção do sujeito de pesquisa}

Tardif (2002) considera que o saber experiencial permite uma avaliação dos demais, por intermédio do seu ajuste em função das condições limitadoras da experiência. Ou seja, os outros saberes se incorporam à prática, que serve como filtro de retomada crítica de saberes constituídos antes e fora da prática profissional.

Assim, salientamos que os saberes experienciais não só fazem parte do conjunto dos saberes, como também constituem, fundamentalmente, uma amálgama de todos eles. Essa visão coloca o trabalho docente não somente como locus de aplicação de saberes, mas principalmente como locus onde eles são produzidos e constantemente reavaliados e ajustados à luz das restrições concretas de produção do trabalho docente. Essa é uma perspectiva dinâmica, em que os conhecimentos e saberes docentes evoluem e se integram na e pela prática docente, como, nos dizeres de Tardif (2002), um conhecimento prático, experiencial.

Nesse sentido, realizamos pesquisa na formação de professores de física para desvelar e explicitar conhecimentos procedimentais e discursivos de ordem prática, que surgem na e pela prática docente. Nossa investigação privilegiou uma abordagem de cunho etnográfico das interações discursivas em sala de aula, que 
permitiu acesso aos significados construídos e compartilhados pelo grupo, ou seja, permitiu alcançar compreensão da dinâmica discursiva a partir da perspectiva do grupo investigado.

Selecionamos o sujeito de pesquisa - o professor formador - com ampla experiência na formação de professores, na educação básica e com tradição de pesquisa sobre interações discursivas de sala de aula. Nossa expectativa era que tais características se traduzissem em uma amálgama experiencial que pudesse ser considerada exemplar, devido às características singulares do professor formador selecionado.

Por meio da abordagem etnográfica, tivemos acesso à prática deste professor formador (daqui em diante chamado "formador") ao gerenciar argumentações; desta prática destacamos um conjunto de "procedimentos discursivos didáticos" (PDD) que pudemos conjugar com determinadas mudanças no desenvolvimento do discurso argumentativo. Isso significa que esses procedimentos podem ser associados à condução do discurso pelo formador, regulada por objetivos didáticos e por condições discursivas que evoluem em mudanças contínuas do discurso.

São essas mudanças que, integradas aos PDD de maneira relacional, coerente e consistente, nos demonstram seu caráter exemplar. Assim, retomando os apontamentos de Borges (2004), o critério para elevarmos os PDD ao status de saberes docentes experienciais repousa sobre o caráter argumentativo deles, assegurado pela sua integração em uma estrutura discursiva dinâmica, relacional, coerente e consistente. Em nosso estudo, portanto, o caráter argumentativo brota das análises dos pesquisadores, que procuram ver a lógica que determinada situação adquire em função das intervenções (procedimentos discursivos, no caso da nossa pesquisa) do professor formador.

É consensual entre os autores que avançam na discussão sobre os saberes docentes que eles muitas vezes revelam-se enquanto saberes inconscientes incorporados à prática cotidiana. Isso traz evidentemente problemas em delimitar o que é saber docente: devemos associá-lo ao que o professor faz ou ao que ele faz e sabe dizer por que fez? Nossa abordagem evita esse problema, na medida em que considera como saber docente aquilo que pode ser justificado em um sentido mais amplo, seja fruto da análise dos pesquisadores ou da consciência do professor sobre suas ações e procedimentos discursivos. Ou seja, o status de saber docente repousa em seu caráter argumentativo.

Agora que consolidamos nossa justificativa para o status de saber docente dos procedimentos discursivos didáticos (PDD) que identificamos na prática do formador, explicitaremos os aspectos teóricos e procedimentos metodológicos 
adotados durante a realização do estudo que conduzimos na formação de professores de física.

\section{A pesquisa desenvolvida na disciplina Prática de Ensino de Física}

O objetivo principal da pesquisa foi caracterizar as situações argumentativas em uma disciplina de Prática de Ensino de Física I (PEF I), com foco nas ações e procedimentos discursivos do professor formador. A escolha da disciplina seguiu o critério da diversidade: a Prática de Ensino de Física pode ser considerada uma disciplina em que há convivência de conhecimentos de vários campos, sendo assim favorável para o estabelecimento de divergências de pontos de vista, o que a literatura tem relacionado à emergência de situações argumentativas (cf. BILLIG, 1996; CHARAUDEAU; MAINGUENEAU, 2004; VIEIRA; NASCIMENTO, 2009a).

A coleta de dados seguiu orientação etnográfica, com registro em notas de campo e áudio e vídeo de uma disciplina de Prática de Ensino de Física que foi ministrada durante um semestre letivo em uma grande e conceituada universidade pública do sudeste do país. A disciplina é obrigatória para todos os alunos do curso de Licenciatura em Física no contexto da universidade onde a pesquisa foi realizada. As aulas aconteceram duas vezes por semana, com duração aproximada de uma hora e quarenta minutos. A matriz curricular da disciplina abrangia várias áreas de conhecimento do campo pedagógico e, em especial, do ensino de ciências. O estágio de observação de 30 horas, que fazia parte da disciplina, foi realizado fora da carga horária semanal de aula, e executado geralmente em duplas em escolas escolhidas pelos licenciados de acordo com suas conveniências e disponibilidades. Foram realizadas duas entrevistas com o formador. A primeira entrevista foi realizada antes do início da disciplina, com o objetivo de obter uma visão ampla do contexto investigado a partir do ponto de vista do formador. Na segunda entrevista utilizamos trechos de vídeos para estimular a memória discursiva do formador sobre eventos selecionados para análise.

Foram selecionados três episódios argumentativos para análise detalhada (VIEIRA, 2007). A partir do registro em áudio e vídeo, foi realizada a transcrição primária de todos os três episódios, seguida de análise proposicional por intermédio dos quadros proposicionais (VIEIRA, 2011), em que cada proposição corresponde à menor unidade de significado do discurso analisado. A análise proposicional informou os procedimentos de enquadramento dos argumentos no padrão de argumento de Toulmin (1958). Na sequência e com o auxílio dos enquadramentos, identificamos um conjunto de PDD do formador nos episódios argumentativos 
analisados. O quadro 01 sintetiza os principais procedimentos discursivos que identificamos nessa análise.

Quadro 01 - Os papéis e procedimentos discursivos didáticos do formador (adaptado de autor, 2007).

\begin{tabular}{|c|c|c|}
\hline $\begin{array}{l}\text { Papel do } \\
\text { formador }\end{array}$ & $\begin{array}{c}\text { Procedimentos } \\
\text { discursivos (PDD) }\end{array}$ & Descrição do procedimento \\
\hline \multirow{3}{*}{$\begin{array}{l}\text { Avaliador de } \\
\text { pontos de } \\
\text { vista }\end{array}$} & $\begin{array}{l}\text { Justificação de um } \\
\text { ponto de vista }\end{array}$ & $\begin{array}{l}\text { Formador apresenta possíveis justificativas e evidên- } \\
\text { cias que podem dar suporte a uma opinião. }\end{array}$ \\
\hline & $\begin{array}{l}\text { Confirmação de ponto } \\
\text { de vista }\end{array}$ & $\begin{array}{l}\text { Formador assegura um ponto de vista ou justificativa } \\
\text { de um licenciando. }\end{array}$ \\
\hline & $\begin{array}{l}\text { Reelaboração de um } \\
\text { ponto de vista }\end{array}$ & $\begin{array}{l}\text { Formador retoma um dado ponto de vista alheio e o } \\
\text { reelabora em sua fala. }\end{array}$ \\
\hline \multirow{6}{*}{$\begin{array}{l}\text { Gerenciador } \\
\text { da discussão }\end{array}$} & $\begin{array}{l}\text { Enunciação de um } \\
\text { ponto de vista }\end{array}$ & Formador articula o seu próprio ponto de vista. \\
\hline & $\begin{array}{l}\text { Sumarização de ideias } \\
\text { discutidas }\end{array}$ & $\begin{array}{l}\text { Formador sintetiza em sua fala ideias, pontos de vista } \\
\text { e justificativas anteriores sobre uma questão prévia. }\end{array}$ \\
\hline & $\begin{array}{l}\text { Enunciação de pontos } \\
\text { de vista contraditórios }\end{array}$ & $\begin{array}{l}\text { Formador articula dois pontos de vista contraditórios } \\
\text { sobre uma mesma questão. }\end{array}$ \\
\hline & $\begin{array}{l}\text { Elaboração de feed- } \\
\text { backs eliciativos }\end{array}$ & $\begin{array}{l}\text { Formador solicita um ponto de vista sobre uma ques- } \\
\text { tão ou pede por maior elaboração. }\end{array}$ \\
\hline & $\begin{array}{l}\text { Interrupção de turnos } \\
\text { de fala dos licencian- } \\
\text { dos }\end{array}$ & $\begin{array}{l}\text { Formador interrompe a fala de um licenciando para } \\
\text { avaliar o que foi dito ou dar sua opinião sobre o as- } \\
\text { sunto em pauta. }\end{array}$ \\
\hline & $\begin{array}{l}\text { Estabelecimento da } \\
\text { última palavra }\end{array}$ & $\begin{array}{l}\text { Formador finaliza a discussão com procedimentos } \\
\text { que redirecionam a atenção da turma para outra ques- } \\
\text { tão. }\end{array}$ \\
\hline Auscultador & Escuta atenta & $\begin{array}{l}\text { Formador se mantém em silêncio prestando atenção } \\
\text { nas trocas discursivas entre os licenciandos. }\end{array}$ \\
\hline
\end{tabular}




\section{III.1 Os Procedimentos Discursivos Didáticos como saberes experienciais}

Os procedimentos discursivos didáticos apresentados no quadro 01 foram considerados saberes experienciais, que identificamos e compreendemos na prática do formador por meio de observação de cunho etnográfico e análise do discurso. Os procedimentos satisfazem o critério de racionalidade, evidenciado pelo seu caráter argumentativo, que passaremos a demonstrar a partir de análises discursivas de um trecho de episódio argumentativo de quatro minutos de duração.

Apesar de o episódio ter duração reduzida, é bastante rico o gerenciamento do discurso pelo formador por meio dos seus procedimentos discursivos didáticos. A estrutura relacional e integrada apresentada na Fig. 1 sintetiza os procedimentos e as respectivas mudanças do discurso após a sua efetivação pelo formador.

Na Fig. 1 (dividida em três fases principais - abertura, desenvolvimento e fechamento), os círculos representam procedimentos discursivos didáticos selecionados, enquanto as setas representam alterações no discurso. Apesar de não podermos afirmar seguramente uma relação de causa e consequência, podemos assumir a correlação entre as mudanças no discurso e os procedimentos. Essa correlação pode ser justificada teoricamente, de modo que podemos assumir o caráter argumentativo e, consequentemente, a natureza de saber docente experiencial dos procedimentos considerados.

Em suma, se formos capazes de compreender e justificar a lógica de articulação entre os procedimentos e as mudanças no discurso e, além disso, associar as correlações identificadas a objetivos didáticos bem estabelecidos, então podemos, seguramente, atribuir o mérito de saber experiencial aos PDD. Por questões de espaço, faremos o exercício de justificar apenas os dois primeiros procedimentos do formador. Uma análise mais detalhada dos demais procedimentos apresentados na Fig. 1 consta em Vieira, Kelly \& Nascimento (2012).

\section{III.2 Análise dos procedimentos "Enunciação de pontos de vista contraditó-} rios" e "Justificação de um ponto de vista"

O episódio em que sucederam os procedimentos analisados ocorreu na nona aula da disciplina observada, teve duração de quatro minutos e foi constituído por vinte e cinco turnos de fala. Na ocasião, estavam presentes dezesseis licenciandos. O motivo da aula era discutir sobre processos de aprendizagem a partir das ideias de Piaget e relacioná-los com o ensino de Física. No início da aula o formador propôs uma atividade para ser realizada em duplas ou tríades, de modo que as seguintes questões fossem respondidas: 


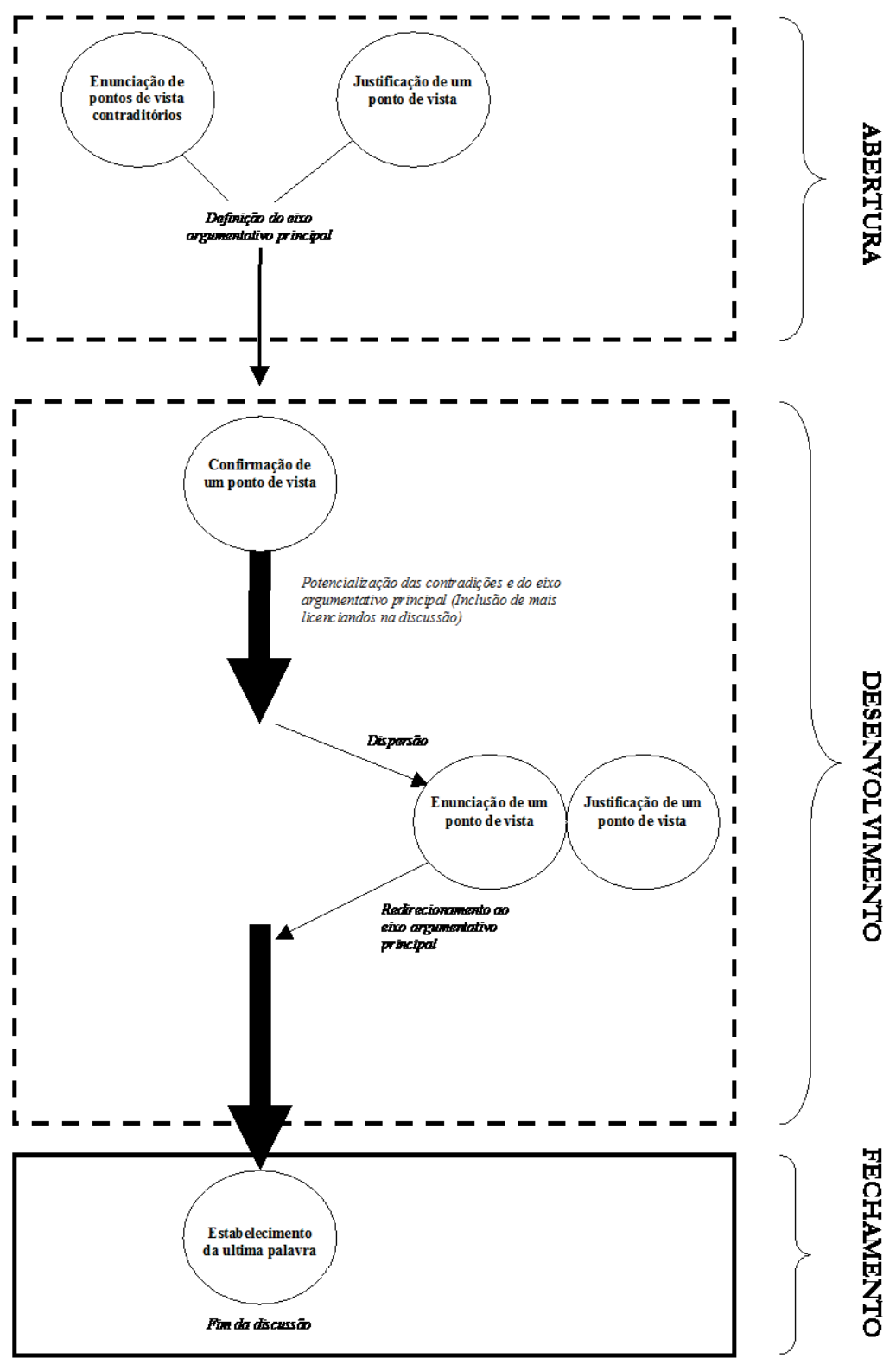

Fig. 1 - Um esquema dinâmico da estrutura procedimental do formador no episódio argumentativo analisado (adaptado de Vieira \& Nascimento, 2009b). 
1) O que fazemos quando aprendemos coisas novas?

2) Como se dá a aprendizagem humana?

Após discutirem as duas questões os grupos apresentaram as suas respostas, que foram anotadas na lousa pelo formador. Durante esse processo o formador fez várias intervenções e comentários. Em uma de suas intervenções, ele salientou a função cognitiva de coordenação de ideias e, para exemplificar, desenhou na lousa o movimento de um corpo lançado verticalmente para cima na superfície da Terra. O episódio teve início a partir da colocação de uma questão pelo licenciando Rui (nas transcrições a numeração se refere aos turnos de fala, as vírgulas sinalizam pausas e as expressões que aparecem entre colchetes trazem esclarecimentos e comentários do transcritor):

1 - RUI: Professor, deixa eu fazer um comentário aqui, quando a velocidade é igual a zero [num lançamento vertical para cima] muito se fala, já vi isso gente falando na televisão e em correção de prova de vestibular que o corpo para, no ponto mais alto da trajetória,

2 - FORMADOR: Eh, quando a gente fala que o corpo para,

3 - RUI: Pois é, o que é parar?,

4 - FORMADOR: Tem dois sentidos, se o sentido do para, significa você permanecer um tempo parado isso tá completamente equivocado, o problema é que isso é ambíguo né?, Se isso significa ter um instante com velocidade nula ela para porque ela estava subindo, não está mais, mas também não está descendo, naquele instante ela tá, com velocidade nula, não é verdade?, O problema é entender que é um instante apenas, um infinitésimo de tempo antes e um infinitésimo de tempo depois ela tá em movimento ou, subindo ou descendo,

No turno de fala 4, em resposta ao questionamento do licenciando Rui, o formador explicita que podem existir dois sentidos para o parar (procedimento de "enunciação de pontos de vista contraditórios"), apresentando duas justificativas para cada um deles (procedimento de "justificação de um ponto de vista"). Desse modo, o formador elabora dois argumentos: um deles a favor do repouso e o outro a favor do movimento de um objeto no ponto mais alto da sua trajetória em um lançamento vertical para cima. Após a articulação desses procedimentos pelo formador, o discurso desdobrou-se em uma argumentação com interação dos estudantes. 
Neste ponto, vamos situar essa discussão na questão dos objetivos didáticos. Avaliamos que a forma como esses procedimentos foram empregados pelo formador pode servir ao objetivo didático de promover uma argumentação. Essa conexão entre intencionalidade didática e procedimentos se justifica em função das características particulares dos argumentos construídos, em que um argumento é a refutação do outro. A refutação, de acordo com Toulmin (1958), cumpre o papel de dar os limites de um determinado argumento. Com isso, compreendemos que a refutação presente na fala de um mesmo interlocutor favorece a relativização de seus pontos de vista, tornando-os mais nivelados, contribuindo assim para diminuir as assimetrias e propiciando oportunidades para o desenvolvimento da argumentação.

Como o formador constrói argumentos que defendem opiniões contraditórias, isso nos levou a reconhecer, sob o critério de coerência, que ele não concorda com uma das opiniões. Inclusive, isso pôde ser atestado ao longo do desenvolvimento da discussão, em que o formador afirma categoricamente que não está de acordo com a opinião que defende o repouso do objeto.

A argumentação desenvolveu-se durante aproximadamente quatro minutos, com apresentação dinâmica de argumentos e contra-argumentos por parte do formador e dos estudantes, até que o formador decidiu finalizar a discussão. $\mathrm{O}$ turno de fala apresentado a seguir parte desse momento:

25 - FORMADOR: Veja, [professor aumenta o volume da sua voz] o que eu to querendo chamar a atenção [professor faz um som (shhhh!)] é que na hora de descrever essa história, nós usamos uma coordenação de uma série de ideias de distância, de tempo, de dividir isso em infinitésimos de vetores de representações de gráficos não é isso?, De taxas de variação, ou seja, usamos uma coordenação de ideias pra dar sentido um sentido novo, pra esse fenômeno tão familiar, tão trivial né? De lançar um objeto para cima e deixá-lo cair, né?, Não é assim?,

O formador finaliza a discussão, mesmo sem haver consenso, quando pede silêncio por meio de uma expressão não lexical "shhh", aumenta o volume da sua voz e estabelece em sua fala uma mudança temática. Assim, esses três recursos funcionam conjuntamente para o "estabelecimento da última palavra".

$\mathrm{Na}$ segunda entrevista realizada com o formador foi possível entender porque ele resolveu fechar a discussão naquele momento, dizendo:

[...] O que havia para aprender com aquela situação já havia sido aprendido $[\ldots]$. 
Pela inspeção da transcrição acima, podemos perceber que o formador reconheceu que houve "oportunidades de aprendizado" na argumentação desenvolvida, apesar dele também sinalizar que essas oportunidades estavam saturadas em um dado momento, sendo que essa foi a razão para ele finalizar a discussão.

\section{Conclusões e implicações para a pesquisa}

Considerando a questão do status de saber docente, foi possível mostrar o caráter argumentativo de dois procedimentos discursivos na forma específica em que foram empregados pelo formador, cumprindo a função de abrir espaço para o desenvolvimento de uma argumentação. Assim, as análises apresentadas colocam esses procedimentos na condição de saberes docentes experienciais, pois evidenciam o caráter argumentativo deles. Acreditamos que esses procedimentos podem se tornar referência para outros formadores e professores em sua prática cotidiana.

Podemos dizer que os conhecimentos teóricos do formador se amalgamaram com outros saberes e com a situação contextual e o orientaram a articular os dois procedimentos discursivos com vistas a promover uma argumentação. Nesse caso, os procedimentos discursivos foram enriquecidos pelos demais saberes e, na medida em que foram explicitados e justificados pela pesquisa, podem vir a tornarse elemento de novas práticas de professores em seu cotidiano de sala de aula. É interessante notar esse movimento do saber experiencial de sair da condição de elemento da prática para a de produto da atividade de pesquisa, e novamente para a de elemento da prática, num movimento dialético de mediação do todo para a parte e da parte para o todo (cf. LEONT'EV, 1981).

Consideramos que a pesquisa deve contribuir para esse movimento dialético assumindo a função de explicitar e justificar os procedimentos discursivos dos professores, racionalizando-os e devolvendo-os para os docentes, que podem reelaborá-los constantemente em sua prática cotidiana. Sob essa perspectiva e conforme aponta Tardif (2013), a pesquisa universitária assume um papel fundamental na atual demanda pela profissionalização do ensino. Nos dizeres do autor:

Em última análise, a profissionalização leva a considerar os professores como especialistas da pedagogia e da aprendizagem, que baseiam suas práticas profissionais em conhecimentos cientificos. Nessa perspectiva, o antigo saber de experiência sobre o qual se fundava a formação nas escolas normais deve dar lugar a conhecimento especializado, baseado na pesquisa universitária. Entretanto, como em medicina ou em engenharia, a pesquisa não se limita a produzir conhecimentos teóricos ou básicos: ela deve 
estar a serviço da ação profissional e resulta em um aumento das competências práticas dos professores. Finalmente, a profissionalização do ensino induz a uma visão reflexiva do ato de ensinar: o ensino não é mais uma atividade que se executa, mas uma prática na qual devemos pensar que devemos problematizar, objetivar, criticar, melhorar (ibdem, p. 561).

Contribuindo para esse importante movimento de profissionalização do ensino, nossa pesquisa busca explicitar os procedimentos discursivos didáticos de professores de ciências em interações instrucionais de salas de aula. Nosso projeto inicial teve como foco as situações argumentativas, e se desdobrou na busca por um mapeamento procedimental mais amplo, envolvendo os procedimentos discursivos mediados por orientações discursivas ${ }^{2}$ descritivas, narrativas, explicativas, dialogais e injuntivas nas várias situações cotidianas de salas de aula de ciências.

Esse programa de pesquisa contribui para a ampliação de um repertório de conhecimentos que Gauthier e colegas (1998) chamam de gestão da matéria e gestão da classe. Um passo importante, como o empreendido neste trabalho, é tirar os procedimentos discursivos do segredo de sala de aula, explicitando-os e justificando-os, de modo a lhes investir de um caráter argumentativo e, com isso, elevando-os à condição de saberes docentes experienciais de referência para a formação e para a prática dos professores.

\section{Referências}

ADAM, J. M. A linguística textual: introdução à análise textual dos discursos. Tradução do original francês. São Paulo: Cortez, 2008. 369p.

BILLIG, M. Arguing and thinking: A rhetorical approach to social psychology. Cambridge: Cambridge University Press, 1996. 325p.

BORGES, C. Os saberes dos docentes como objeto de estudo. Araraquara: JM Editora, 2004. 317p.

\footnotetext{
2 Orientação discursiva é um conceito derivado de estudos sobre as sequências textuais, sistematizadas por Jean-Michel Adam (2008). Uma orientação discursiva (narrativa, descritiva, argumentativa, explicativa, injuntiva ou dialogal) caracteriza-se por uma estrutura linguística que media e conforma as práticas discursivas dos sujeitos participantes ao mesmo tempo em que é produzida e reproduzida por essas práticas. Assim, uma determinada orientação discursiva oferece o campo de possibilidades e restrições para a fala, e pode, portanto, ser pensada como um instrumento psicológico para a ação humana. Essa perspectiva é descrita em detalhes em outro trabalho (VIEIRA; KELLY; NASCIMENTO, 2012).
} 
CHARAUDEAU, P.; MAINGUENEAU, D. Dicionário de análise do discurso. Tradução do original francês. São Paulo: Contexto, 2004. 555p.

GAUTHIER, C.; MARTINEAU, S.; DESBIENS, J.-F.; MALO, A.; SIMARD, D. Por uma teoria da pedagogia: pesquisas contemporâneas sobre o saber docente. Tradução do original francês. Ijuí: Unijuí, 1998. 480p.

LEONT'EV, A. N. Problems of the development of the mind. Moscow: Progress Publishers, 1981. 455p.

SHULMAN, L. Those who understand: Knowledge growth in teaching. Educational Researcher, v. 15, n. 2, p. 4-14, 1986.

TARDIF, M. A profissionalização do ensino passados trinta anos: dois passos para a frente, três passos para trás. Educação \& Sociedade, v. 34, n. 123, p. 551-571, 2013.

TARDIF, M. Saberes docentes e formação profissional. 8. ed. Petrópolis: Vozes, 2002. 325p.

TARDIF, M. Saberes profissionais dos professores e conhecimentos universitários. Revista Brasileira de Educação, n. 13, p. 5-24, 2000.

TOULMIN, S. Os usos do argumento. Tradução do original inglês. São Paulo: Martins Fontes, 2001. 375p.

VIEIRA, R. D. Discurso em salas de aula de ciências: Uma estrutura de análise baseada na teoria da atividade, sociolinguística e linguística textual. 2011. 139f. Tese (Doutorado em Educação) - Faculdade de Educação, UFMG, Belo Horizonte.

VIEIRA, R. D. Situações argumentativas na abordagem da natureza da ciência na formação inicial de professores de física. 2007. 173f. Dissertação (Mestrado em Educação) - Faculdade de Educação, UFMG, Belo Horizonte.

VIEIRA, R. D.; KELLY, G. J.; NASCIMENTO, S. S. An activity theory-based analytic framework for the study of discourse in science classrooms. Ensaio: Pesquisa em Educação em Ciências, v. 14, n. 2, p. 13-46, 2012. 
VIEIRA, R. D.; NASCIMENTO, S. S. Uma proposta de critérios marcadores para identificação de situações argumentativas em salas de aula de ciências. Caderno Brasileiro de Ensino de Física, v. 26, n. 1, p. 81-102, 2009a.

VIEIRA, R. D.; NASCIMENTO, S. S. Uma visão integrada dos procedimentos discursivos didáticos de um formador em situações argumentativas de sala de aula. Ciência e Educação, v. 15, n. 3, p. 443-457, 2009b. 